\title{
MOŽNOSTI RAZVOJA ROGLE NA POHORJU $Z$ VIDIKA PRIMERNOSTI POKRAJINE ZA REKREACIJO
}

\author{
Uroš Horvat *
}

IZVLEČEK

UDK 911.3:379.8(234.321-43)

Prispevek predstavlja $v$ prvem delu osnovna izhodišca in značilnosti metode vrednotenja primernosti pokrajine za rekreacijo, $v$ drugem delu pa rezultate vrednotenja primernosti Rogle na Pohorju za izbrane rekreacijske aktivnosti in iz tega izhajajoče možnosti nadaljnjega razvoja.

ABSTRACT

UDC 911.3:379.8(234.321-43)

DEVELOPMENTAL PROSPECTS OF ROGLA ON THE POHORJE MOUNTAIN IN VIEW OF ITS SUITABILITY FOR RECREATION

The first part of the article is concerned with the basic premises and features of the methods for the evaluation of landscape in view of its suitability for recreation. In the second part, evaluation results for selected recreational activities on Rogla on Pohorje are presented. Developmental prospects of the area are also addressed.

\section{UVOD}

Obmoxja, ki so namenjena za turizem in rekreacijo, pridobivajo vedno vecji pomen, saj sedanje življenjske navade, tehnieni napredek in splošni gospodarski razvoj vplivajo na Sirjenje turizma in rekreacije tako $\mathrm{v}$ regionalnih kot $\mathrm{v}$ mednarodnih okvirih. $\mathrm{V}$ obmoxjih, ki izkazujejo višjo stopnjo primernosti se $\mathrm{z}$ razlißnimi vlaganji pospešuje turistixni razvoj in se obenem ome jujejo dolocene dejavnosti in odpravljajo moteci dejavniki. Z razlienimi posegi v pokrajino, ki jo uporabljata turizem in rekreacija, postajata obe dejavnosti poleg industrializacije in urbanizacije, eni od najpomembnejsih vplivnih dejavnikov preoblikovanja pokrajine in to večinoma $\mathrm{v}$ prirodno visoko ocenjenih obmoxjih, s privlačnostmi, ki so hkrati tudi ekološko močno občutljive.

V zadnjih dvajsetih letih je bilo razvitih nekaj metod, s pomoxjo katerih lahko ovrednotimo primernost pokrajine za izvajanje posameznih rekreacijskih aktivnosti ali skupin rekreacijskih aktivnosti (Empirische ..., 1980; Kiemstedt, 1973; Kiemstedt, 1977; Wiemann, 1985). V zacetku so predstavljale bolj inventarizacijo razlicnih sestavin pokrajine, zlasti tistih, ki obstajajo v pokrajini zaradi turizma in rekreacije, nato pa so se razvile v sodobne kvantitativne metode, $\mathrm{ki}$ so naslonjene na uporabo računalnika.

\footnotetext{
* Mag, stažist raziskovalec, Oddelek za geografijo, Pedagoška fakulteta, Univerza v Mariboru, Koroška cesta 160,62000 Maribor, Slovenija.
} 
Osnovni cilji vecine metod, s katerimi lahko vrednotimo primernost pokrajine za rekreacijo, so sledeci:

1 - podati pregled pokrajinskih pogojev za izvajanje pomembne jsih rekreacijskih aktivnosti

2 - prostorsko omejiti obmocja primernosti glede na možne rekreacijske aktivnosti

3 - razvrstiti možna obmoxija po stopnjah primernosti.

Čeprav so bile kvantitativne metode zaradi svoje nedorečenosti, razlið̌nih izhodiš̌ in segmentov vrednotenja deležne stevilnih in mnogokrat upravið̌enih kritik, pa je njihova prednost ta, da nam omogočajo z dokaj objektivnim ocenjevalnim postopkom, na kvantitativen naxin, določiti in omejiti tista obmoxja, ki izkazujejo določeno stopnjo primernosti za rekreacijo, oziroma posamezne rekreacijske aktivnosti.

Navedenim ciljem sledi tudi metoda, ki sem jo uporabil za vrednotenja primernosti pokrajine za rekreacijo (Horvat, 1990) in jo preizkusil na nekaterih primerih. V tem prispevku so na osnovi uporabljene metode podani rezultati vrednotenja primernosti Rogle na Pohorju.

\section{METODOLOŠKA IZHODIŠČA}

Osnovna izhodišca uporabljene metode vrednotenja so sledeca:

1 - vrednotenje temelji na vrednotenju primernosti za posamezne rekreacijske aktivnosti, saj so razlixne rekreacijske aktivnosti odvisne od razlicnih pokrajinskih pogojev.

2 - razvoj rekreacijskih aktivnosti ni odvisen le od naravnega potenciala, temvec tudi od turisticne infrastrukture in superstrukture, dostopnosti območ ja, idr.

3 - metoda je od, v literaturi objavljenih metod, relativno najmanj subjektivna, saj se subjektivnosti pri določanju teže posameznih kriterijev ter seštevanju ocen v veliki meri izognemo s hierarhǐ̌nim sistemom združevanja kriterijev ter razvršanjem ocen na osnovi vrstilne lestvice. Tako končni rezultat ne temelji na povprečku ali vsoti ocen posameznih kriterijev, temvex na kombiniranju ocen kriterijev, ki jih s pomočjo redukcije izražamo $\mathrm{v}$ Stirih primernostnih stopnjah.

4 - hierarhiðni sistem združevanja kriterijev in uporaba računalnika nam omogocata fazno vrednotenje, vse delne in koněne rezultate pa lahko tudi kartografsko prikažemo, kar povečuje preglednost (Jeršic, 1985).

Vrednotenje temelji na vrednotenju primernosti pokrajine za posamezne rekreacijske aktivnosti. Izbrane so bile le tiste oblike rekreacije, ki so pomembnejše in dostopne siršm plastem prebivalstva. To so: alpsko smucanje, tek in hoja na smuceh, sprehajanje, hoja ter pocitek $\mathbf{v}$ naravi.

Izbor kriterijev je prilagojen vrednotenju vsake rekreacijske aktivnosti posebej. Dolocenih je 18 kriterijev, ki so loceni na nujne in dopolnilne kriterije (tabela 1). Enaki kriteriji so uporab- 
ljeni pri razlixnih rekreacijskih aktivnostih, zato so za vsako posebej doloceni minimalni zahtevnostni nivoji in primernostne stopnje kriterijev. Kriteriji so na osnovi vrstilne lestvice opredeljeni s Stirimi primernostnimi stopnjami, pri Cemer so $\mathbf{v}$ Cetrti stopnji vrednosti, ki ne dosegajo minimalnega zahtevnostnega nivoja za izvajanje posameznih rekreacijskih aktivnosti.

Primernostne stopnje so opredeljene:

1 - zelo visoka primernost

2 - visoka primernost

3 - zadovoljiva primernost

4 - brez posebne primernosti

Izvedba vrednotenja poteka po matrikah zdrǔ̌evanja kriterijev (K) v skupine kriterijev (SK) in zveze skupin kriterijev (ZSK) (tabela 2). V matrikah so opredeljeni hierarhienni sistemi združevanja kriterijev in določanja primernostnih stopenj na posameznih nivojih vrednotenja.

Končni rezultat vrednotenja je izražen tako, da so za vsako posamezno osnovno prostorsko enoto vrednotenja določene stiri primernostne stopnje oziroma ocene primernosti za izvajanje posameznih rekreacijskih aktivnosti. Na njihovi osnovi z združevanjem celic, ki izkazujejo enake primernostne stopnje določimo primernostna obmoxja za izvajanje teh aktivnosti.

\section{ANALIZA PRIMERNOSTI ROGLE NA POHORJU ZA IZBRANE REKREACIJSKE AKTIVNOSTI}

Zreško Pohorje zavzema osrednji južni del Pohorskega pogorja. Najvišji vrhovi (Rogla 1517 $\mathrm{m}$, Planinka $1529 \mathrm{~m}$ ) se le rahlo dvigajo nad okoliskimi planotami in se pocasi znižujejo proti vzhodu. Najvecji planoti sta Konjiska planja pri Rogli in Vitanjska planja na Pesku. Severozahodno od Rogle ležijo na planoti Lovrenška jezera, ki jih obdaja močvirni gozd, zaradi česar je to obmoxje težje prehodno. Proti jugu poboxje polagoma in deloma $v$ terasah pada. Vanj so se globoko zajedli visoko izvirajoci potoki in ga razrezali v več hrbtov, na katerih se nahajajo razložena naselja. Najviša med njimi sta Skomarje (944 m) in Resnik (932 m).

Jugozahodno od vrha Rogle se je razvil eden večjih rekreacijsko - turistiænih centrov v Sloveniji - to je RTC Unior, katerega upravlja Unior iz Zrex. Jedro centra predstavlja hotel Planja (zgrajen leta 1981) $\mathrm{z}$ depandanso, bungalovi in Sportnimi objekti, $v$ okolici pa so številne pocitniške hišice podjetij iz Slovenije in od drugod. Število ležišc in noxitev se vsako leto povečuje. Tako so leta 1981 registrirali 23.679 nočitev na 116 ležiščih, leta 1989 pa kar 116.608 nočitev na preko 1.000 ležiš̌cih. Pozimi 13 vlečnic in 2 sedežnici s skupno zmogljivostjo preko 12.000 smucarjev na uro omogočajo smuko, poleti pa privlačna okolica, bogata tudi z gozdnimi sadeži, omogoča sprehode in sprostitev v naravi.

V vrednotenje sem vkljuxil obmoxje veliko približno $20 \mathrm{~km}^{2}$ (508 celic v velikosti $200 \times 200$ 
m) ki se razprostrira v smeri sever - jug od Lovrenških jezer na severu do južno od RTC Unior ja in nato $\mathrm{v}$ ozkem pasu do južnih pobocij Pohorja do najviSjega naselja Resnik, $\mathrm{v}$ katerem je nekaj turistiænih kmetij in vikendov. V smeri zahod - vzhod pa se razprostira od izvira Mislinje do spodnje postaje sedežnice Jurgovo.

Alpsko smučanje se je v zadnjih tridesetih letih uveljavilo kot množična rekreacijska aktivnost. Tudi RTC Unior je prvenstveno namenjen tej aktivnosti, ki zahteva specifiene pokrajinske pogoje in ustrezno zimsko-sportno infrastrukturo. Ker pa je stopnja razvitosti odvisna predvsem od naravnih pogojev, sem posvetil najve` pozornosti vrednotenju pokrajinske primernosti za alpsko smučanje.

Stopnjo pokrajinske primernosti sem dolocil s tremi skupinami kriterijev. Ker se Rogla nahaja v sredogorju, sodi v obmoxje zelo visoke primernosti, glede zanesljivosti snežne odeje, le greben nad $1500 \mathrm{~m}$ nadmorske visine, medtem ko izkazuje vecina obmox ja 2. stopnjo primernost.

Obsežen planotast svet okoli Rogle je zaradi majhnih naklonov zemljisča neprimeren za alpsko smučanje. Zelo visoko primernost izkazujejo le južna poboxja Pohorja in poboxja proti dolini Mislinje na zahodu, Radoljne na severu in Oplotnice na vzhodu, kjer so tudi visinske razlike smučrskih območij med $150-400 \mathrm{~m}$ in ponekod tudi nad $400 \mathrm{~m}$. Vendar je južno poboxje Pohorja prisojno in ima v višnah pod $1300 \mathrm{~m}$ nižjo klimatsko primernost.

Pomembna je tudi raba tal. $\mathbf{Z}$ zelo visoko primernostjo so ocenjena območ ja med $0 \%$ do najvec $50 \%$ gozdnih povrSin. Ta \e omogočajo urejanje novih smuxarskih prog brez unicevanja sklenjenega gozda.

S kombiniranjem ocen vseh treh skupin kriterijev dobimo oceno ZSK pokrajinske primernosti za alpsko smuxanje. Večina celic se uvrš̌a v 3. in 4. stopnjo primernosti. Le nekaj celic izkazuje visoko in zelo visoko primernost.

V vrednotenje so vkljucene se tri ZSK. Te upostevajo vse objekte za bivanje in prehrano gostov ter obstoječe rekreacijske objekte in naprave. $\mathrm{Z}$ njihovim vkljucevanjem $\mathrm{v}$ vrednotenje lahko ugotovimo stopnjo izkorišcenosti primarnih turistiænih dobrin in razvitosti turistiæne infrastrukture. Zadnja ZSK opredeljuje motece dejavnike, pri katerih upoštevamo vse tiste dejavnike, zaradi katerih je onemogoxeno izvajanje alpskega smucanja. Vendar na Rogli ni posebnih motecih de javnikov.

S kombiniranjem ocen vseh ZSK sem določil primernostna obmoxja za alpsko smucanje. Pri tem je imela najveðjo težo ocena pokrajinske primernosti. Vecina območja, ki je že izkorišcena za alpsko smucanje, izkazuje 2. stopnjo primernosti in je namenjena manj in srednje zahtevnim smucarjem. Posebej lahko izlocimo dve obmoxji $z$ visoko primernostjo: 


\section{- obmoxje med Ostruscica, vrhom Rogle in dolino Radoljne}

- območje vzhodno od vrha Rogle proti dolini Oplotnice (Jurgovo)

Vsa ostala obmoxja (preko $87 \%$ celic) sodijo v obmocja s 3. in 4. stopnjo primernosti (povsem neprimernih je kar $53 \%$ vseh celic vrednotenja) Primernost zmanjšjejo predvsem majhni nakloni zemljišca in kratke denivelacije; kjer pa so nakloni večji, je strnjen gozd ali južna pobočja.

Poleg alpskega smučnja je tek in hoja na smučch najpomembne jł̌ in najbolj razsirjena zimsko-sportna rekreacijska aktivnost. Obenem pa je za njeno izvajanje potrebna znatno tanjła snežna odeja in manjša vlaganja $v$ rekreacijske objekte in naprave.

Za to aktivnost je pomembna zlasti reliefna primernost. Planotast svet okoli Rogle je idealen za izvajanje te rekreacijske aktivnosti, saj izkazuje kar $51 \%$ vseh celic vrednotenja zelo visoko primernost naklonov zemljišca. Večna celic ima tudi primerno ekspozicijo, saj prevladujejo severne, zahodne in vzhodne ekspozicije. Kot dopolnilni kriterij je upostevana tudi razglednost, ki pa je na Rogli vecja le na planjah.

Glede rabe tal za tek in hojo na smuceh izkazuje Rogla zelo visoko in visoko primernost (gozdovi, pašniki, travniki). Najprimernejša so obmox̌ja z do $50 \%$ gozda, ceprav se lahko izvaja tudi v sklenjenem gozdu, ce so tekaske proge ure jene po gozdnih poteh.

V vrednotenje so poleg vrednotenja pokrajinske primernosti vkljucene se stiri ZSK. Poudarek je predvsem na vrednotenju poti. Zajete so bile vse oznacene in lokalne poti ter ravni pohodni tereni. Rogla je prepredena s potmi, ki so prisotne kar v $72 \%$ celic. Obenem pa je veliko celic tudi pohodnih. V zimskem casu je zato možna ureditev stez za tek in hojo na smuceh razlicnih težavnostnih stopenj v skupni dolžini preko $30 \mathrm{~km}$. Vrednotimo jih v ZSK - rekreacijski objekti.

S kombiniranjem ocen vseh ZSK sem določil primernostna območja za tek in hojo na smuceh. Za Roglo lahko ugotovimo, da prevladujejo zelo primerni pogoji za izvajanje te rekreacijske aktivnosti. V območje z zelo visoko in visoko primernostjo se je uvrstilo kar $41 \%$ vseh obravnavanih celic. Na visoko primernost vplivajo tako ugodne klimatske razmere $\mathrm{z}$ dražilno klimo, primerna debelina snežne odeje, ugodna reliefna razgibanost (zlasti naklon zemljiš̌a) ter višnski pašniki, ki prehajajo $\mathrm{v}$ gozd, prepreden $\mathrm{s}$ številnimi potmi. Ta pokrajinski potencial je izkoriš̌en $z$ ureditvijo številnih stéz za tek in hojo na smučeh. Posebej lahko izloximo naslednja obmoxja z zelo visoko primernostjo:

- obmoxje med sedlom Komisija, Ostrušcico in hotekm Planjo

- obmox̌je od sedla Komisija proti Lovrenškim jezerom 
- obmox́je od hotela Planja proti Kraguljišcu

- obmoxje od hotela Planja proti vrhu Rogla in proti

Konjiški planji.

Sprehajanje je ena od osnovnih rekreacijskih aktivnosti. Primerna je za vecino obiskovalcev turističnega obmoxja. Vezana je na privlačna in pokrajinsko pestra obmoxja, ki imajo obenem razvito turistið̌no infrastrukturo in Številne izletniške cilje. Večnoma se izvaja v kombinaciji z drugimi dejavnostmi, zlasti z obiski določenih obmox̌ij, ogledom naravnih in kulturnih znamenitosti, pocitkom $v$ naravi, ipd..

Rogla, ki je bila leta 1989 razglašena za klimatsko zdravilišce, izkazuje zelo visoko stopnjo klimatske primernosti.

Za vrednotenje sprehajanja je izredno pomembna reliefna primernost. Najbolj primerni nakloni (do najvec $15 \%$ ) zajemajo na Rogli preko $50 \%$ vrednotenih celic, katerih večna ima tudi primerne ekspozicije (J, Z, V). Stopnjo pokrajinske primernosti znižuje edino slaba razglednost. Razgledi se ponujajo zgolj na plani površini in $\mathrm{z}$ najvisjih vrhov ali iz redkega gozda na pobocjuih.

V vrednotenje so poleg vrednotenja ZSK pokrajinske primernosti, vkljuðene se stiri ZSK (poti, turistǐ̌ni objekti za bivanje in gostinstvo, motexi dejavniki in oddaljenost od izhodišnnih tock). Po mnenju stevilnih avtorjev je sprehajanje večnoma omejeno na trajanje 1,5 - 2 uri. $\mathrm{Na}$ Rogli se znotraj te izohrone nahaja vecina obmoxja.

S kombiniranjem ocen vseh ZSK sem dolocil primernostna obmoxja za sprehajanje, ki zajemajo $37 \%$ vseh celic vrednotenja. Ta so:

- obmoxje od Volovske planje preko Ostruščice do hotela

Planja

- obmoxje od hotela Planja proti Kraguljišxu

- območje od hotela Planja preko vrha Rogle do Konjiske planje in Peska.

Hoja je najbolj razširjena rekreacijska aktivnost, ki omogoxa udeležencem neposreden stik z naravo. Za izvajanje so primerna zlasti pokrajinsko pestra obmoxja, z razgibanim reliefom in $\mathrm{z}$ relativno visoko stopnjo ohranjenosti naravnih pokrajinskih prvin. Sama hoja se razlikuje od planinarjenja, za katerega značilno tudi premagovanje večjih viSinskih razlik.

Stopnjo pokrajinske primernosti za hojo sem dolocil s štirimi SK. Reliefno primernost določjo kriteriji: naklon zemljišca, ekspozicije zemljiša in razglednost. Rogla izkazuje glede na prva dva kriterija zelo visoko in visoko primernost, vendar je v oceni skupine kriterijev zmanjß̌na primernost zaradi majhne razglednosti in izostanka izrazitih vrhov, ki bi omogočili premagovanje večjih višinskih razlik. 
Pri rabi tal so viŠje ocenjena obmoxja, ki niso povsem gozdnata, saj gozdni robovi in spreminjanje rabe tal povečujejo pokrajinsko pestrost. Dopolnilna skupina kriterijev za opredelitev pokrajinske primernosti je SK - naravna in kulturna dedišina. Ogledi teh objektov lahko predstavljajo vmesne in kon๔ne tocke med izvajanjem te aktivnosti.

S kombiniranjem ocen vseh stirih SK dobimo oceno pokrajinske primernosti za hojo. Vecji del Rogle (37\% vseh vrednotenih celic) izkazuje zelo visoko primernost. To potr jujejo tudi ocene ZSK - poti, ki predstavljajo temeljno infrastrukturo za izvajanje te rekreacijse aktivnosti. Na Rogli so poti prisotne kar v $72 \%$ vseh celic. S tem se povecuje notranja dostopnost pokrajine.

S kombiniranjem ocen vseh క̌tirih ZSK doloximo primernostna obmoxja za hojo. Veðji del Rogle ( $80 \%$ vrednotenih celic) izkazuje zelo visoko in visoko primernost za hojo, saj ima Rogla, zaradi zaoblenih vrhov, poboxij zmernih strmin in menjave travnih povrsin in gozda, zelo pohodna zemljišca, razen tega pa je tudi prepredena s potmi. Na obmoðju Rogle se stika ve` transverzalnih poti, kar omogoča celodnevno hojo iz večjega števila izhodišnnih in $\mathrm{k}$ veð ciljnim točkam.

V sklopu počitka $\mathbf{v}$ naravi sem določal primernostna obmoxja za taborjenje in razne igre $\mathbf{v}$ naravi. Poleg reliefnih razmer (dovolj velik obseg ravnih povrsin) je za izvajanje teh aktivnosti potrebna primerna raba tal (zlasti travnate povrsine, gozdni robovi in jase v gozdu). Pohodnost zemljiša in prisotnost voda కe povečata pokrajinsko primernost.

Zelo visoko in visoko stopnjo reliefne primernosti imajo obmoxja $\mathrm{z}$ naklonom zemljišca med 0 - $5 \%$ oziroma do $10 \%$; z južno, vzhodno in zahodno ekspozicijo in ravnimi povrsinami v velikosti vsaj $5000 \mathrm{~m}^{2}$. Zelo visoko primernost glede rabe tal izkazujejo travnata obmoxja in obmoxja z gozdnimi robovi ter vodotoki.

$\mathrm{V}$ vrednotenje so poleg vrednotenja pokrajinske primernosti vkljucene tudi ZSK poti, turistirni objekti za bivanje in gostinstvo ter moteči dejavniki.

S kombiniranjem ocen vseh štirih ZSK sem določil primernostna obmoxja za poxitek v naravi. Na Rogli se je v območja z zelo visoko in visoko primernostjo uvrstilo $11 \%$ vrednotenih celic, ki jih lahko razdelimo $v$ dve skupini:

- večje obmoxje okoli hotela Planja proti Ostrušcici in

vrhu Rogle (to obmoxje je urejeno za to aktivnost, saj

je ob gozdnih robovih postavljenih veđ kamnitih ognjišc)

- posamezna manja območja na Volovski plánji, Kraguljišcu, vrhu Rogle, Konjiški planji, Pesku in

Mašin žagi 


\section{Z.AKIJUČEKK}

$\mathrm{Z}$ uporabljeno metodo vrednotenja sem na Rogli na Pohorju izlocil posamezna primernostna obmox̌ja za smucanje, tek na smuð̌eh, sprehajanje, hojo ter pocitek v naravi. Med vsemi rekreacijskimi aktivnostmi izkazuje Rogla na Pohorju najvisjo stopnjo primernosti za hojo ( 80 $\%$ vrednotenega obmoxja je ocenjeno $\mathrm{z}$ zelo visoko in visoko primernostjo), tek na smureh ( $41 \%$ ) in sprehajanje (37\%). Za alpsko smuđanje je primernih $12 \%$ vrednotenega obmođja, za pocitek v naravi pa $11 \%$. Dolocena obmǒ̌ja so že izkoriš̌ena (zlasti za alpsko smucanje), za ostale rekreacijske aktivnosti pa so nakazane možnosti nadaljnjega razvoja in Sirjenja. Pri tem nam rezultati lahko služijo kot podlaga za nadaljnje usklajevanje razlǐnnih konceptov rabe prostora.

Ker se je Rogla na Pohorju v zadnjih desetih letih razvila v pomembno turisticno obmoxje Slovenije, se to odraža tudi v izkorišcanju ti. primarnih turistǐ̌nih dobrin. Število obiskovalcev na Rogli narašca in vedno bolj pridobiva na pomenu tako zimska kot poletna sezona. Velik obisk pa vpliva tudi negativno, saj naravovarstveniki že ugotavljajo škodljive posledice turistične rabe. $\mathrm{V}$ bližini hotela in na najbolj izpostavljenih obmoxjih je uničeno rastiše ruševca in velikega petelina. Zato naj bi bilo v prihodnje sirక̌e zaledje Rogle zašciteno kot regijski park, kar je potrebno upoštevati tudi pri strategiji nadaljnjega razvoja.

\section{LITERATURA IN VIRI}

Debelak M., 1976, Rekreacija v naravi, primernost in zmogljivost prostora, Urbanistǐni inštitut SRS, Ljubljana

Empirische Untersuchungen zur ausseren Abgrenzung und inneren Struktuierung von Freizeitrăumen, 1980, Forschungs- und Sitzungsbericht, Band 132, Hannover

Horvat U., 1990, Vrednotenje primernosti pokrajine za turizem in rekreacijo, Ljubljana (magistrsko delo)

Jerßǐ M., 1985, Turistǐ̌na geografija, Ljubljana

Kiemstedt H., in sodelavci, 1973, Landschaftsbewertung für Erholong im Sauerland, Inst. für Landschaftsbau TU Berlin, Berlin

Kiemstedt H., 1977, Bewertung des landschaftlichen Standortpotentials für Freizeit und Erholong, Geografija turizma in regionalno prostorsko planiranje, Geographica Slovenica 5, Ljubljana

Wiemann A., 1985, Eine Erholungsart- und Aktivităts- spezifische Freiraumbewertung Südhessens, Rhein-Mainische Forschungen, H.102, Frankfurt am Main 


\section{DEVELOPMENTAL PROSPECTS OF ROGLA ON THE POHORJE MOUNTAIN IN VIEW OF ITS SUITABILITY FOR RECREATION}

In the past twenty years a number of methods for the evaluation of landscape suitability for individual recreational activites as well as for their groups have been developed. These methods allow for a relatively objective evaluation as well as for a quantitative determination and delimitation of those areas that are characterized by a certain degree of suitability for recreational activities.

The article presents the basic premises and features of the method used. This is based on the hierarchical system of grouping individual criteria and on determining the suitability degrees according to the individual levels of evaluation. In this way the final result is not based on the mean value or on the sum of all the individual evaluation criteria, but is rather a combination of criteria evaluations. It consists of four suitability degrees.

The method was used to determine individual areas on Rogla on Pohorje (north-eastern Slovenia) that differed among themselves according to their suitability for recreational activities. The selected activities were alpine skiing, cross-country skiing, walking, hiking and outdoor relaxation. The highest degree of suitability was shown for hiking ( $80 \%$ of the area evaluated was graded highly suitable or suitable), follow cross-country skiing (41\%) and walking (37 \%). $12 \%$ of the area was suitable for alpine skiing, and $11 \%$ for outdoor relaxation. Certain areas have already been put to use, especially for alpine skiing. For other recreational activities, though, there is room for further development and expansion. The results of this study therefore serve as a basis for future coordination between various concepts dealing with ways of exploiting the landscape. 
Tabela 1

Seznam izbranih kriterijev (K), skupin kriterijev (SK) in zvez skupin kriterijev (ZSK)

List of selected criteria (K), groups of criteria (SK) and of joined groups of criteria (ZSK)

rekreacijske aktivnosti:

AS - alpsko smucanje

TS - tek in hoja na smuxeh

S - sprehajanje

$\mathrm{H}$ - hoja

PN - počitek v naravi

\section{1 - nujni (pogojni) kriteriji}

2 - dopolnilni (pomožni) kriteriji kriterij

K 1 - bioklimatska primernost

K 2 - trajanje primerne snežne odeje

K 3 - naklon zemljišca

K 4 - visinska razlika smučrarskega obmox̌ja

K 5 - ekspozicija zemljišca

K 6 - razglednost

K 7 - obseg ravnih površin

K 8 - raba tal

K 9 - gozdnatost

K 10 - dostopni vodni rob

K 11 - naravna dedišcina

K 12 - kulturna dedišcina

K 13 - poti

K 14 - turistiæni objekti za bivanje in gostinstvo

K 15 - oddaljenost od izhodišnnih tock

K 16 - urejena smučišca

K 17 - ure jene steze za tek na smuceh

K 18 - motexi dejavniki
AS TS $\mathrm{S} \quad \mathrm{H} \quad \mathrm{PN}$

$\begin{array}{lllll}2 & 2 & 2 & 2 & 2 \\ 1 & 1 & - & - & - \\ 1 & 1 & 1 & 1 & 1 \\ 1 & - & - & - & - \\ 1 & 1 & 2 & 2 & 1 \\ - & 2 & 2 & 1 & - \\ - & - & - & - & 1 \\ - & 1 & 1 & 1 & 1 \\ 1 & 1 & 1 & 1 & 1 \\ - & - & 2 & - & 2 \\ - & - & 2 & 2 & - \\ - & - & 2 & 2 & - \\ - & 1 & 1 & 1 & 2 \\ 2 & 2 & 2 & 2 & 2 \\ - & - & 1 & - & - \\ 2 & - & - & - & - \\ - & 2 & - & - & - \\ 1 & 1 & 1 & 1 & 1\end{array}$


skupina kriterijev

AS TS $\mathrm{S} \quad \mathrm{H} \quad \mathrm{PN}$

SK 1 - klimatska primernost

SK 2 - reliefna primernost

SK 3 - raba tal

SK 4 - vodotoki in vodne povrSine

. . . . . . . . . . .

SK 5 - naravna in kulturna dedišcina

SK 6 - poti

SK 7 - turistieni objekti za bivanje in gostinstvo

SK 8 - rekreacijski objekti

SK 9 - oddaljenost od izhodišcnih tock

SK 10 - moteči de javniki

$\begin{array}{ccccc}1 & 1 & 2 & 2 & 2 \\ 1 & 1 & 1 & 1 & 1 \\ 1 & 1 & 1 & 1 & 1 \\ - & - & 2 & - & 2 \\ - & - & 2 & 2 & - \\ - & 1 & 1 & 1 & 2 \\ 2 & 2 & 2 & 2 & 2 \\ 2 & 2 & - & - & - \\ - & - & 1 & - & - \\ 1 & 1 & 1 & 1 & 1\end{array}$

zveza skupin kriterijev

AS TS $\mathrm{S} \quad \mathrm{H} \quad \mathrm{PN}$

ZKS 1 - pokrajinska primernost

ZKS 2 - poti

ZKS 3 - turistieni objekti za bivanje in gostinstvo

ZKS 4 - rekreacijski objekti

ZKS 5 - oddaljenost od izhodišnnih tock

ZKS 6 - motexi dejavniki

$\begin{array}{lllll}1 & 1 & 1 & 1 & 1 \\ - & 1 & 1 & 1 & 2 \\ 2 & 2 & 2 & 2 & 2 \\ 2 & 2 & - & - & - \\ - & - & 1 & - & - \\ 1 & 1 & 1 & 1 & 1\end{array}$


tabela 2: Matrika združevanja kriterijev za tek in hojo na smučeh

Table 2: Matrix for the joining together of the criteria for cross-country skiing

\section{TEK IN HOJA NA SMUČEH}

ZSK 1/2 - POKRAJINSKA PRIMERNOST

SK $1 / 2$ - klimatska primernost

K $1 / 1$ - bioklimatska primernost

K $2 / 2$ - trajanje primerne snežne odeje

SK $2 / 2$ - relief na primernost
K $3 / 2$ - naklon zemljišča
K $5 / 2$ - ekspozicija zemljišča
K 6 - razglednost

SK $3 / 2$ - raba tal

K 8 - raba tal

K $9 / 2$ - gozdnatost

\section{ZSK 2 - POTI}

SK 6 - poti

K 13 - poti

ZSK 3 - TURISTIČNI OBJEKTI ZA BIVANJE IN GOSTINSTVO

SK 7 - turistični objekti za bivanje in gost.

$\mathrm{K} 14$ - turistični objekti za bivanje in gost.

ZSK 4/2 - REKREACIJSKI OBJEKTI

SK $8 / 2$ - rekreacijski objekti

K 17 - urejene steze za tek na smučeh

ZSK 6 - MOTEČI DEJAVNIKI

SK 10 - moteči dejavniki

K 18 - moteči dejavniki 
Primernost Rogle na Pohorju za tek in hojo na smučeh Suitability of Rogla on The Pohorje Mountain for cross-country skiiing

\section{TEK IN HOJA NA SMUČEH}

iz: ZSK $1 / 2$ - pokrajinska primernost

ZSK 2 - poti

ZSK 3 - turistični objekti za bivanje in gostinstvo

ZSK $4 / 2$ - rekreacijski objekti

ZSK 6 - moteči dejavniki

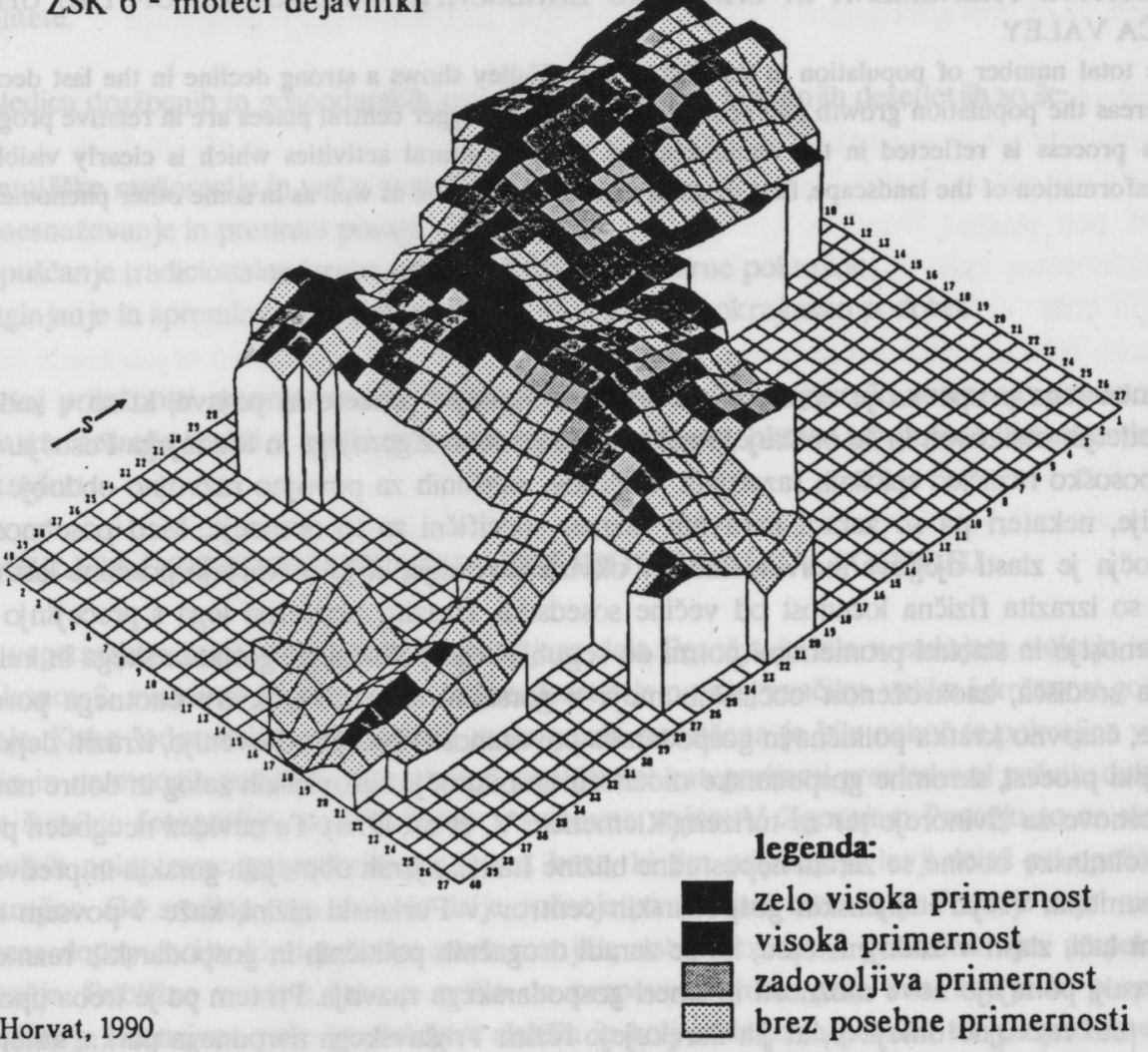

